\title{
Size Control Of Nanographene Supported Iron Oxide Nanoparticles Enhances Their Electrocatalytic Performance For The Oxygen Reduction And Oxygen Evolution Reactions
}

Ferdinand Hof, ${ }^{\mathrm{a}, \mathrm{b}}$ Meng Liu, ${ }^{\mathrm{c}}$ Giovanni Valenti, ${ }^{\mathrm{c}}$ Emmanuel Picheau ${ }^{\mathrm{a}, \mathrm{c}}$ Francesco Paolucci, ${ }^{\mathrm{c}}$

Alain Pénicauda,b

a. CNRS, Centre de Recherche Paul Pascal (CRPP), UMR 5031,F-33600 Pessac, France.

b. Université Bordeaux, CRPP, UMR 5031, F-33600 Pessac, France

c. University of Bologna, Department of Chemistry "G. Ciamician”, via Selmi 2, 40126, Bologna, Italy 


\section{Instruments:}

Raman spectroscopy. Raman spectroscopic characterization was carried out on a Horiba Jobin Yvon Xplora microscope equipped with a cooled Andor CCD detector; excitation wavelength: $532 \mathrm{~nm}$, calibration on HOPG, laser spot size of $\sim 1 \mu \mathrm{m}, 1200$ lines per mm grating, objective Olympus 50x LWD. Raman mappings were performed with a motorized $x-y \mu m$ scanning table. 1681 individual spectra were recorded on each sample. Calculations were performed using Labspec6 and Origin 9.2.

$X$-ray powder diffraction (XRD). XRD patterns were collected on a Rigaku Nanoviewer (XRF microsourcegenerator, MicroMax007HF), with a 1200W rotating anode coupled to a confocal Max-FluxOsmic Mirror (Applied Rigaku Technologies, Austin, USA) and a MAR345 image plate detector (MARResearch, Norderstedt, Germany); samples were filled into glass capillaries and were exposed to the X-ray beam ; the detector was placed at a distance of $156 \mathrm{~mm}$ providing access to $2 q$ angles in the range between $0.9^{\circ}$ and $48^{\circ}$.

Thermo gravimetric characterization (TGA). Thermo gravimetric characterization was performed on a TA Q50 TGA. Between 6-8 mg of composite sample was weighed in a Pt-crucible. The measurements were performed under synthetic air $\left(\mathrm{N}_{2} 80 \%, \mathrm{O}_{2} 20 \%\right)$ between $30-800^{\circ} \mathrm{C}$ with a heating rate of $10^{\circ} \mathrm{C} / \mathrm{min}$.

Transmission electron microcopy (TEM): TEM measurements were performed on a TEM-FEG HR (JEOL 2200FS). TEM grids have been prepared by drop casting $20 \mu \mathrm{l}$ of nanocomposite dispersion in THF directly onto SF400-CU(silicon monoxide membranes on 400 mesh copper grid, (Electron microscopy science)) or S166-3 Lacey carbon film (300 mesh copper grid (Agar Scientific)) TEM grids.

X-ray photoelectron spectroscopy (XPS): A ThermoFisher Scientific K-ALPHA spectrometer was used for surface analysis with a monochromatized AlKa source (hv = $1486.6 \mathrm{eV}$ ) and a 200 microns spot size. A pressure of $10^{-7} \mathrm{~Pa}$ was maintained in the chamber during analysis. The full spectra $(0-1150 \mathrm{eV})$ were obtained with constant pass energy of $200 \mathrm{eV}$ and high resolution spectra at constant pass energy of $40 \mathrm{eV}$. Charge neutralization was applied for all samples. High resolution spectra were fitted and quantified using the AVANTAGE software provided by ThermoFisher Scientific and the Scofield sensitivity factors available from the internal database 


\section{Electrochemical measurements:}

The electrochemical properties of $\mathrm{Fe}(\mathrm{nP}) / \mathrm{nC}$ were evaluated in a three-electrode cell composed of a glassy carbon rotating disk electrode (RDE, Tacussel, France) as support for the deposition of different catalyst inks, a SCE reference electrode and a Pt wire auxiliary electrode. The whole characterizations were performed with a SP-300 bipotentiostat (Biologic Instruments) electrochemistry workstation equipped with an additional current booster and a built-in electrochemical impedance spectroscopy (EIS) analyzer. The $\mathrm{Fe}(\mathrm{np}) / \mathrm{nC}$ powders were dispersed in THF $\left(0.5 \mathrm{mg} \mathrm{mL}^{-1}\right)$ and drop casted (50 uL) onto RDE. Meanwhile, the $\mathrm{Fe}(\mathrm{np}) / \mathrm{nC}$ powders were also dispersed in $\mathrm{H}_{2} \mathrm{O}$ and isopropanol (the volume ratio of $\mathrm{H}_{2} \mathrm{O}$ and isopropanol was 3 to 1) $\left(5 \mathrm{mg} \mathrm{mL}^{-1}\right)$ with $50 \mathrm{uL} 5$ $w t \%$ Nafion and drop casted (13.8 uL) onto RRDE. The ORR and OER performances were tested separately by independent experiments in $\mathrm{O}_{2}$-saturated $0.1 \mathrm{M}$ ultrapure $\mathrm{KOH}$ (99.99\%, Sigma-Aldrich) solution and the $\mathrm{pH}$ was verified before each experiment. The potential corrected for the ohmic drop ix $R_{S}$ ( $i$ is the current measured and $R_{S}$ is the uncompensated resistance) measured by impedance spectroscopy at the open circuit potential before each experiment.

Koutecky-Levich (K-L) equation:

$$
\frac{1}{j}=\frac{1}{j_{L}}+\frac{1}{j_{K}}=\frac{1}{0.62 n F C_{0}\left(D_{0}\right)^{2 / 3} v^{-1 / 6} \omega^{1 / 2}}+\frac{1}{n F k C_{0}}
$$

where $j_{K}$ is the kinetic-limiting current density, $n$ is the electron transfer number, $F$ is the Faraday constant $\left(96485 \mathrm{C} \mathrm{mol}^{-1}\right), C_{0}$ and $D_{0}$ are the bulk concentration and diffusion coefficient of $\mathrm{O}_{2}$ in electrolyte $\left(C_{0}, 1.2 * 10^{-6} \mathrm{~mol} \mathrm{~cm}^{-3} ; D_{0}, 1.9 * 10^{-5} \mathrm{~cm}^{2} \mathrm{~s}^{-1}\right.$ in $\left.0.1 \mathrm{M} \mathrm{KOH}\right)$, $v$ is the kinematic viscosity of the electrolyte $\left(0.01 \mathrm{~cm}^{2} \mathrm{~s}^{-1}\right.$ in $\left.0.1 \mathrm{M} \mathrm{KOH}\right), \omega$ is the angular velocity $(\mathrm{rad} / \mathrm{s})$, and $k$ is the electron-transfer rate constant. $j_{K}$ can be achieved from the intercept of K-L equation.

The percentage of current due to $\mathrm{H}_{2} \mathrm{O}_{2}$ production recorded by the ring electrode $\left(\mathrm{X}_{\mathrm{H}_{2} \mathrm{O}_{2}}\right)$ and the corresponding electron transfer number during ORR $\left(n_{e^{-}}\right)$are

$$
\begin{gathered}
X_{H_{2} O_{2}}=\frac{2 I_{R} / N}{I_{D}+I_{R} / N} \\
n_{e^{-}}=\frac{4 I_{D}}{I_{D}+I_{R} / N}
\end{gathered}
$$

, where $I_{R}$ is the ring current, $I_{D}$ is the disk current, and $N$ is the collection efficiency $(25.8 \%)$. 


\section{Chemicals:}

All chemicals have been purchased from Sigma Aldrich.

THF was purified prior use by means of Pure Solv 400-4-MD solvent purification system that is attached directly to the Glove box.

Iron(II)tetrafluoroborate was recrystallized twice inside the glove box prior use.

\section{Graphite starting materials:}

\section{Flake graphite:}

A natural, crystalline flake graphite have been obtained from Asbury Carbons Grade 3061 (mesh $50+$ ). The carbon content is $>99 \%$ and the ash content is less than $0.1 \%$.

\section{Micrographite:}

A micrographite have been obtained from Nacional de grafite grade micrograf 99503UJ (about $3 \mu \mathrm{m}$ in grain size). The carbon content is $99.5 \%$ and the ash content is less than $0.1 \%$.

\section{Graphitic nano carbon (nC):}

Graphitic nano carbons have been obtained from FGV, Cambrige Nanosystems, Grade CamGraph ${ }^{\circledR}$ G1. The carbon is from synthetic origin, Carbon content $>95 \%$ and no inorganic impurities have been found by means of TGA measurement. 


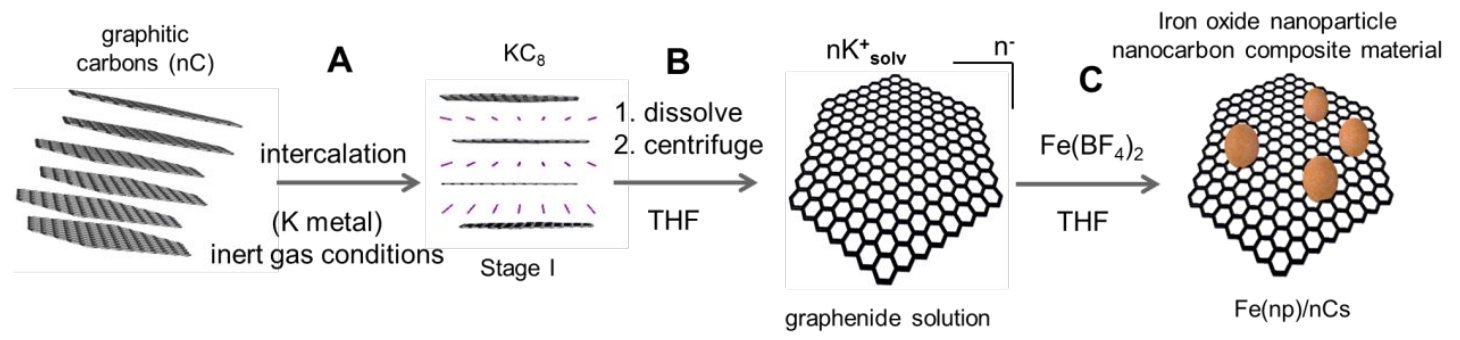

Scheme S 1 Complete reaction scheme for the synthesis of iron oxide nanoparticles. The synthesis involves A) the intercalation of a different graphite starting materials (see section below for details). B) the dissolution towards graphenide solutions and C) the reaction with equimolar amounts of recrystallized iron (II) tetrafluroborate.. In the following aqueous work up step,metallic nanoparticle are oxidized and the final composite materials $(1, \mathrm{~m}, \mathrm{~s})-(\mathrm{Fe}(\mathrm{nP}) / \mathrm{nC})$, based on the carbon used (graphitic nano carbon (s), micrographite $(\mathrm{m})$, and flake graphite (1) are obtained.
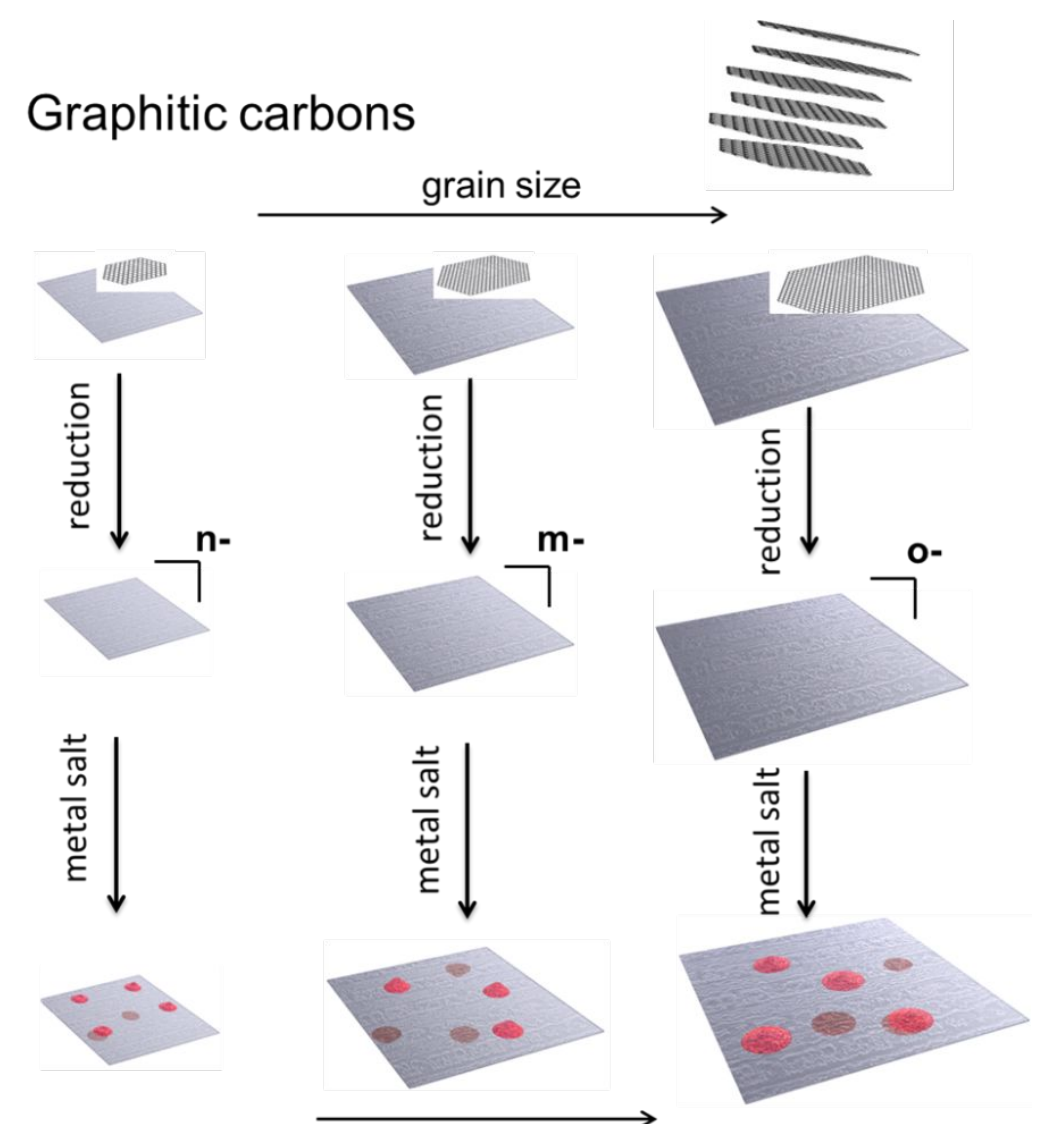

Nano particle size

Scheme $\mathbf{S} 2$ Graphenide solutions with varing lattice size distributions can be obtained by using 3 different types of graphite materials, graphitic nano carbon, micrographite and a flake graphite. These three graphenide solutions serve as reduction agent for iron(II) tetrafluoroborate salts leading to the formation of nanoparticles attached to the carbon framework in each case. The synthesized composite materials exhibit different size distributions of iron oxide nanoparticles, increasing in the orders $\mathrm{s}-(\mathrm{Fe}(\mathrm{nP}) / \mathrm{nC})$, over $\mathrm{m}-(\mathrm{Fe}(\mathrm{nP}) / \mathrm{nC})$ to $1-(\mathrm{Fe}(\mathrm{nP}) / \mathrm{nC})$, observing a variation of size distribution of about one order of magnitude. The control over the particle formation process is provided by the size of the charged graphene layers 
in solution. This observation highlights the remarkable degree of control that the charged graphene layers in solution provide over the redox process and the nanoparticle growth establishing a unique method to control the size of nanoparticles attached to different carbon flakes. 


\section{Synthesis details}

\section{Synthesis of intercalation compound (A)}

$120 \mathrm{mg}(10.0 \mathrm{mmol})$ of each graphite, and $48.8 \mathrm{mg}(1.25 \mathrm{mmol})$ cleaned potassium (stoichiometry $\left.\mathrm{KC}_{8}\right)$ were placed together in a vial inside an argon filled glove box and heated for 5 hours at $180^{\circ} \mathrm{C}$ on a heating plate under occasional stirring. Afterwards, the vial was allowed to cool down to room temperature and the three intercalated graphites $\left(\mathrm{KC}_{8}\right)$ were collected.

\section{Safety remark:}

The possible user of the presented synthetic protocol is reminded of the specific dangers related to the use of potassium metal. Safety precautions are advised for storage, handling and waste treatment.

Potassium metal is extremely dangerous in contact with water or moisture, releasing hydrogen with sufficient heat to cause ignition or explosion. Peroxide formation may occur in containers that have been opened and remained in storage. May produce corrosive solutions on contact with water.

\section{Dispersion of intercalated graphites $\left(\mathrm{KC}_{8}\right)$ and isolation of the graphenide solution (B)}

$150 \mathrm{mg}$ of the as prepared intercalated graphite $\left(\mathrm{KC}_{8}\right)$ were mixed with $150 \mathrm{~mL}$ of absolute THF under inert conditions in a $250 \mathrm{~mL}$ Erlenmeyer flask and the dispersion was stirred for 3 days by the aid of a glass coated magnetic stirring bar. Then the dispersion was centrifuged at $3500 \mathrm{rpm}$ for 30 min under inert conditions and the faint yellowish upper solution was retained in each case. The concentration of each sample have been determined individually by filtering $100 \mathrm{~mL}$ of each through a $0.2 \mu \mathrm{m}$ PTFE membrane filter in the glove box.

\section{Synthesis of the composite compound $(\mathrm{s}, \mathrm{m}, \mathrm{l})-\mathrm{Fe}(\mathrm{nP}) / \mathrm{nC}(\mathrm{C})$}

The as prepared graphenide solutions have been used directly as reduction agent for the $\mathrm{Fe}(\mathrm{nP}) / \mathrm{nC}$ composite synthesis. The graphenide solutions are used as reduction agent, generating s- $\mathrm{Fe}(\mathrm{nP}) / \mathrm{nC}$ from the graphitic nano carbon, $\mathrm{m}-\mathrm{Fe}(\mathrm{nP}) / \mathrm{nC}$ from the micrographite and $\mathrm{I}-\mathrm{Fe}(\mathrm{nP}) / \mathrm{nC}$ from the flake graphite.

Equimolar amounts of recrystallized metal(II) chloride dissolved in $10 \mathrm{~mL}$ of absolute THF were added dropwise to $100 \mathrm{~mL}$ graphenide solution in a $250 \mathrm{~mL}$ Erlenmeyer flask inside an argon filled glove box. After 5-15 min, aggregation and precipitation occurred and the respective dispersion was stirred for 24 hours. Afterwards, the dispersion was centrifuged in the glove box (4000 RPM / 20 min) and the supernatant was removed. The samples have been redispersed in THF followed by another centrifugation step (4000 RPM / 20 min). Afterwards the samples have been removed from the glove box and $20 \mathrm{~mL}$ of distilled water was added. The sample has been added to a separation funnel with $20 \mathrm{~mL}$ of cyclohexane and has been extracted 3 times with distilled water. The samples have been collected via filtration (0.2 $\mu \mathrm{m}$ filter membranes) and dried in vacuum. 


\section{Additional physio-chemical characterization:}
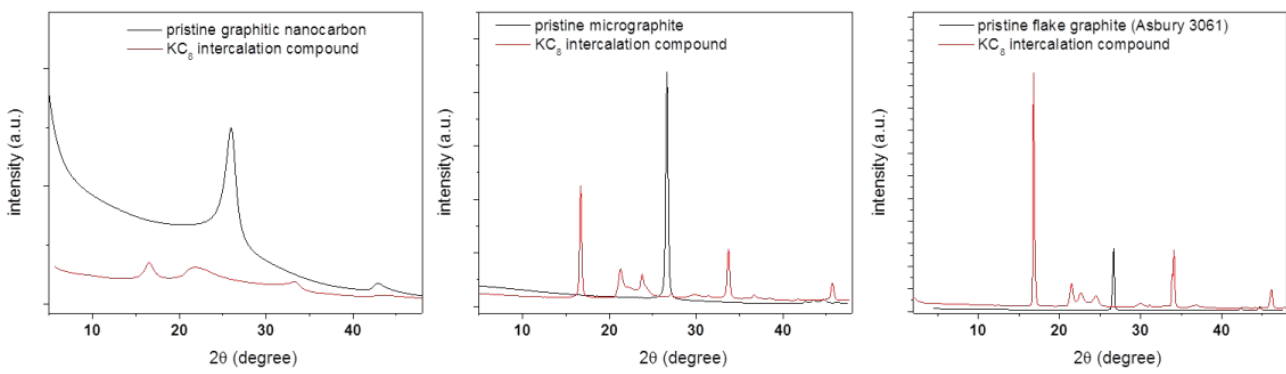

Figure S 1 XRD measurements $(\mathrm{Cu} \mathrm{K}-\alpha)$ of the 3 different starting carbons, black traces, in comparison to the three intercalation compounds of the respective samples, red traces. The characteristics peaks of the graphite (200) peak at about 26 of the different graphites have been fitted and compared with the fits of the intercalation compounds (see Table ST2).

The stage 1 intercalation compound $\left(\mathrm{KC}_{8}\right)$ of each carbon is generated by the direct reaction of the graphite with potassium metal and confirmed by XRD measurements (Fig S1, ESI). The laminar structure of each intercalation compound is visible clearly and each component contains the characteristics bands at about $16.8^{\circ}$ and $35.6^{\circ}$ corresponding to the characteristic interlayer spacing of about $5.3 \AA$. The decrease of crystalline ordering from the natural graphite to the graphitic nanocarbon is observed in respect to their peak line widths (Table ST1, ESI) of both the starting graphites but also in the respective intercalation compounds

Table ST 1 Fitting of the characteristics peaks of the three different graphite starting materials and the 3 stage 1 intercalation compounds. The interlayer distances have been calculated using the Bragg equation $(\mathrm{Cu} \mathrm{K}-\alpha)$.

\begin{tabular}{|c|c|c|c|}
\hline Sample & Peak & FWHM & distance $(\AA)$ \\
\hline graphitic nano carbon (002) & 25.75 & 1.896 & 3.46 \\
\hline graphitic nano carbon (100,101) & 42.97 & 1.311 & 2.10 \\
\hline $\mathrm{KC}_{8}$ graphitic nano carbon (001) & 16.51 & 1.1929 & 5.36 \\
\hline $\mathrm{KC}_{8}$ graphitic nano carbon (002) & 33.09 & 1.92646 & 2.70 \\
\hline micrographite (002) & 26.63 & 0.332 & 3.34 \\
\hline Micrographite (100,101) & 44.67 & 0.436 & 2.03 \\
\hline KC 8 micrographite (001) & 16.68 & 0.281 & 5.31 \\
\hline $\mathrm{KC}_{8}$ micrographite (002) & 33.71 & 0.336 & 2.66 \\
\hline Flake graphite (002) & 26.65 & 0.25 & 3.34 \\
\hline Flake graphite (100,101) & 44.68 & 0.341 & 2.02 \\
\hline $\mathrm{KC}_{8}$ Flake graphite (001) & 16.80 & 0.208 & 5.27 \\
\hline $\mathrm{KC}_{8}$ Flake graphite (002) & 34.04 & 0.361 & 2.63 \\
\hline
\end{tabular}



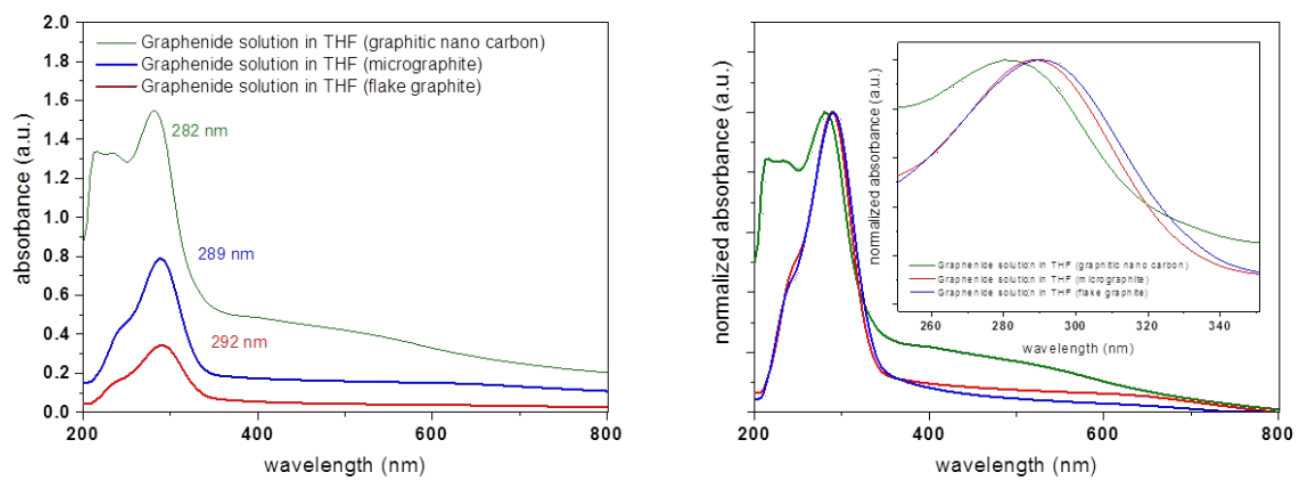

Figure S 2 UV-vis measurement of the different graphenide solutions, diluted by a factor of 10 with anhydrous THF. The total absorbance is higher for the smaller carbon samples and lower for the medium and the larger carbon size. The peak position is slightly different for each sample.

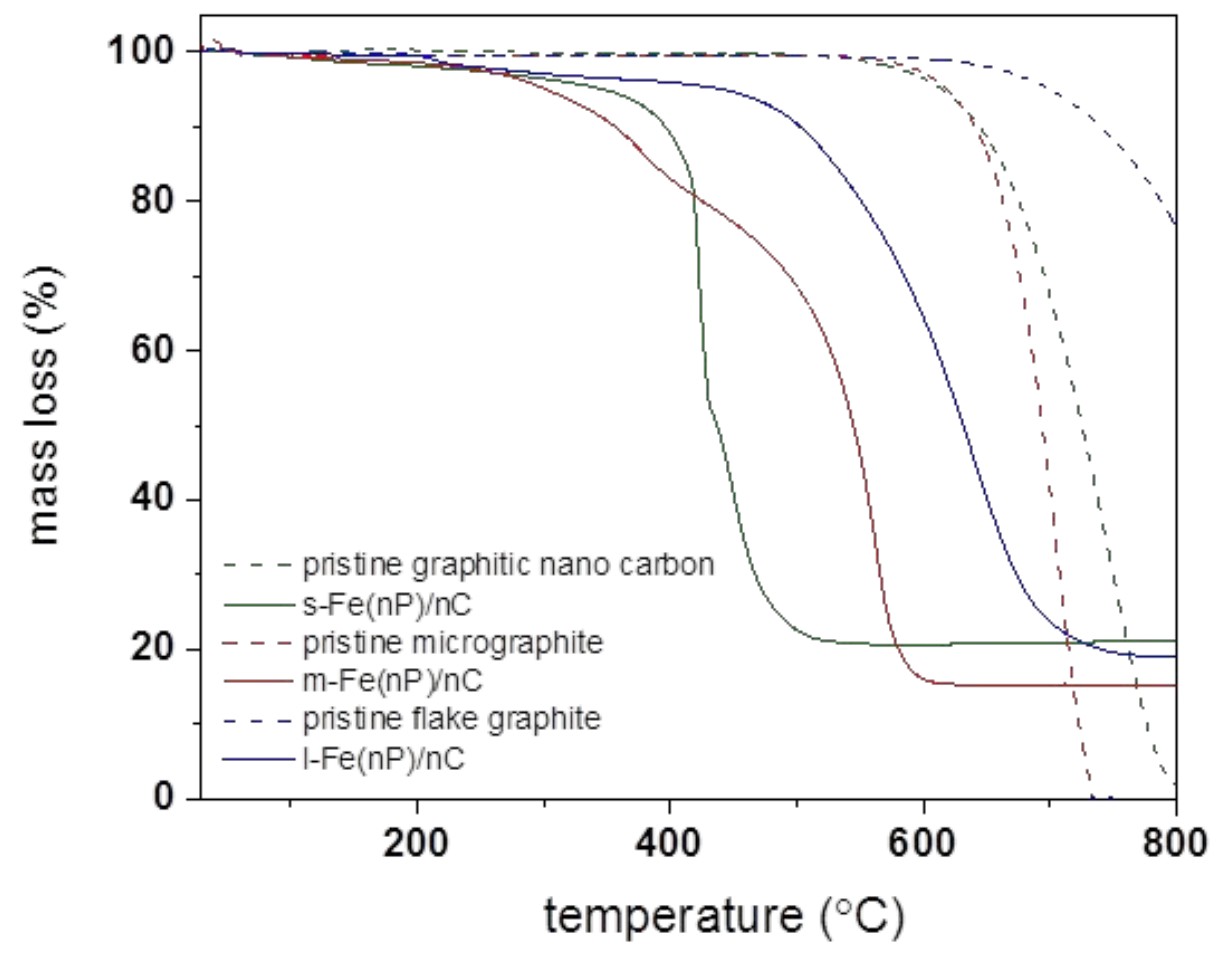

Figure S 3 TGA measurements of the 3 starting graphites, traced lines, in comparison to the 3 composite materials $(\mathrm{s}, \mathrm{m}, \mathrm{l})-\mathrm{Fe}(\mathrm{nP}) / \mathrm{nC}$ in synthetic air $\left(80 \% \mathrm{~N}_{2}, 20 \% \mathrm{O}_{2}\right)$ between $30-800^{\circ} \mathrm{C}$. 

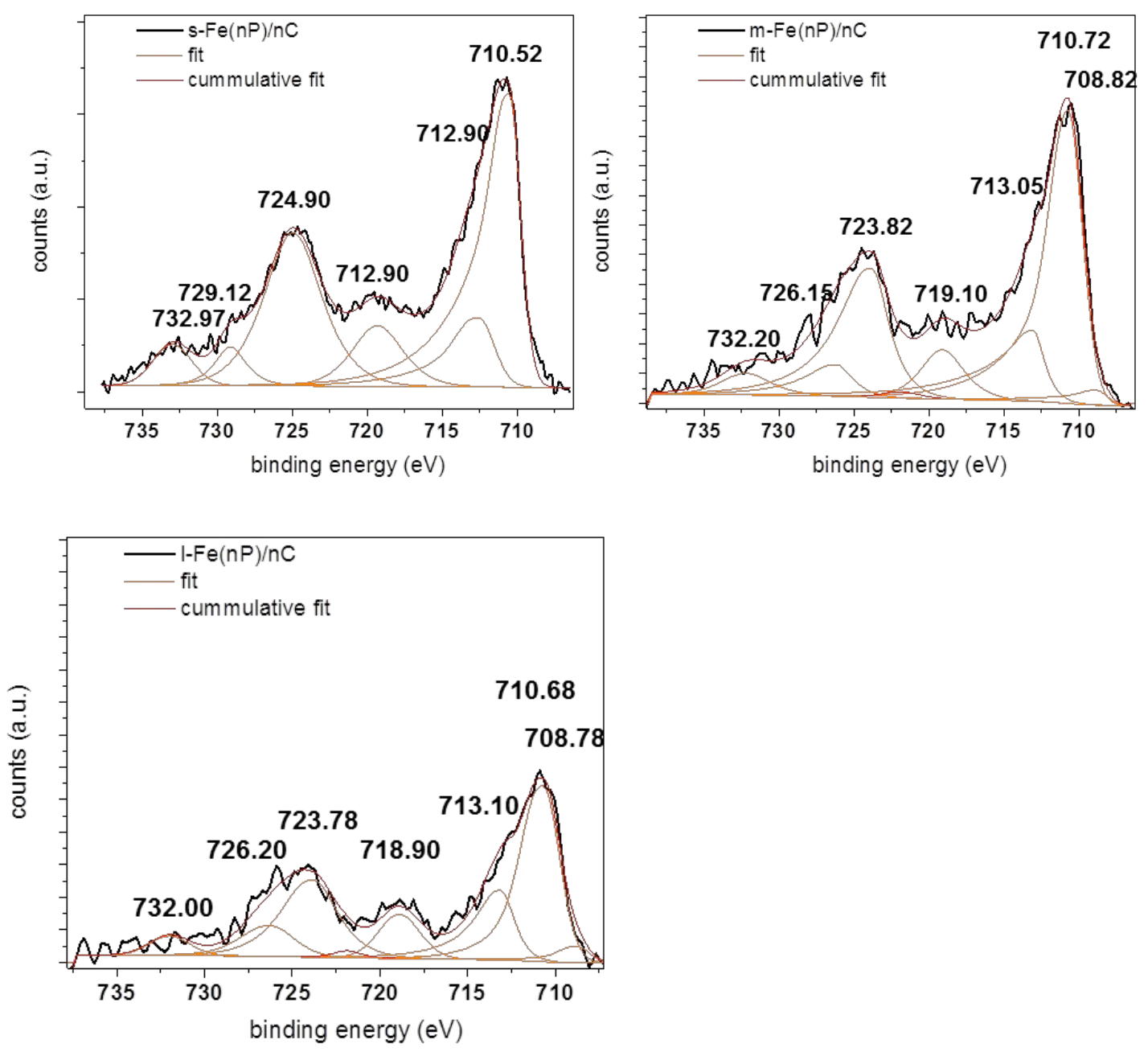

Figure $\mathrm{S} 4$ a) Fits of the $\mathrm{Fe}_{2 \mathrm{P}}$ XPS spectra of the three different composite materials. 

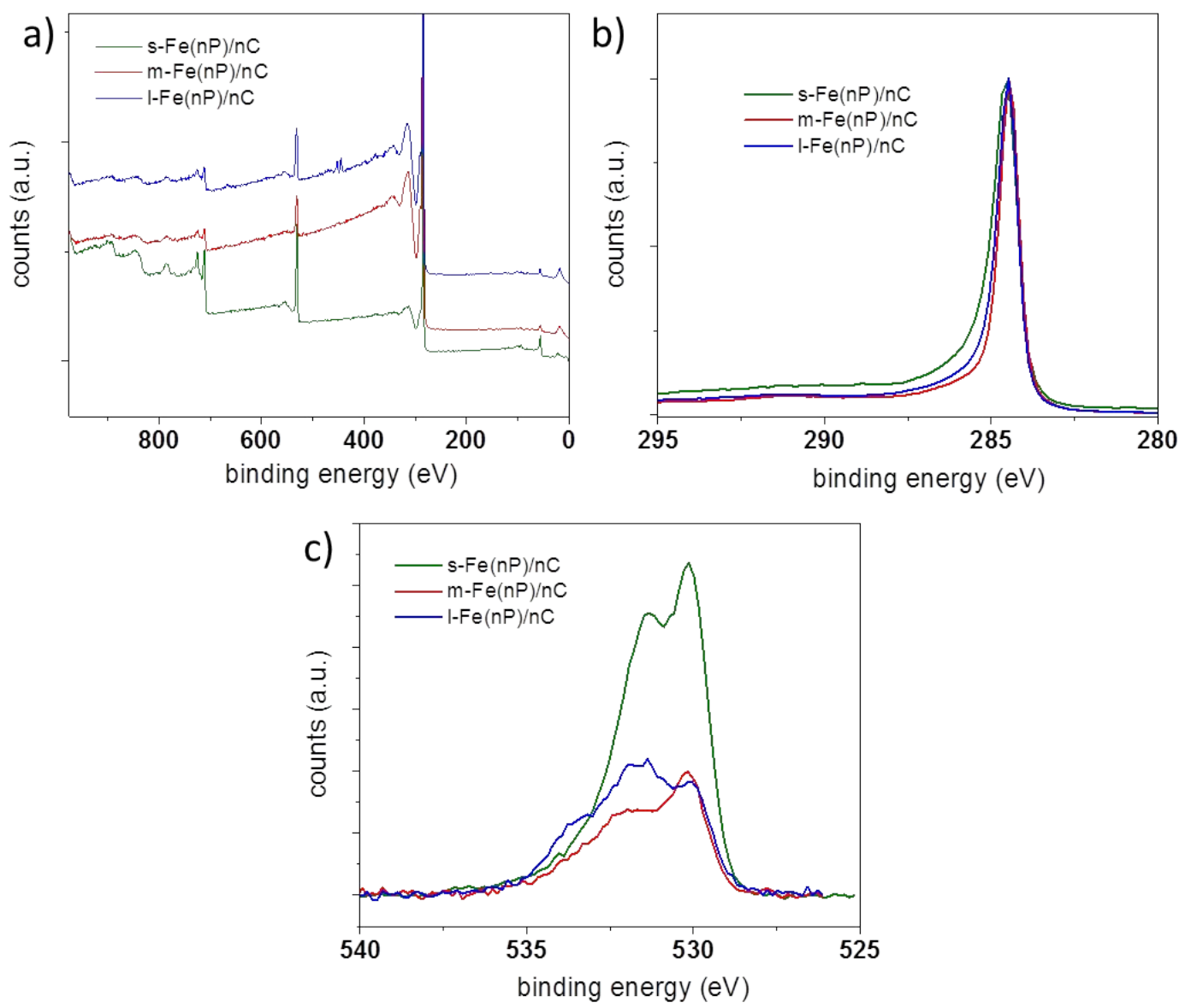

Figure S 5 a) Survey XPS scan demonstrating that the 3 different composite materials exhibit only peaks that are related to carbon, oxygen and iron. b) high resolution XPS spectra in the carbon $\mathrm{C}_{1 \mathrm{~s}}$ region c) high resolution XPS spectra of the oxygen $\mathrm{O}_{1 \mathrm{~s}}$ region.

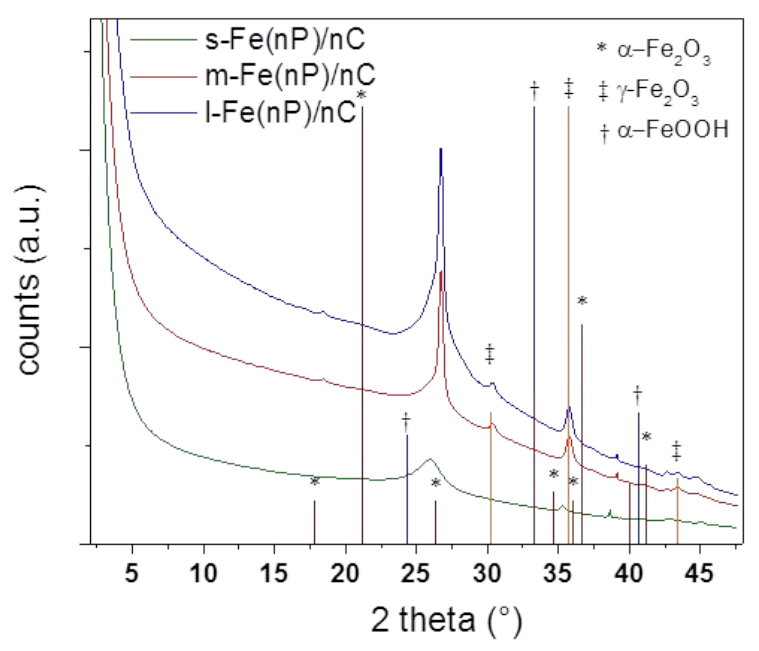

Figure S 6 XRD analysis $(\mathrm{Cu} \mathrm{K}-\alpha)$ of the three different composite samples and comparison to the most likely iron oxide phases from literature data. ${ }^{[1]}$ 
${ }^{[1]}$ R. M. Cornell, U. Schwertman, The Iron Oxides: Properties, Reactions, Occurrence, and Uses, VCH, Weinheim, Germany, 1996.
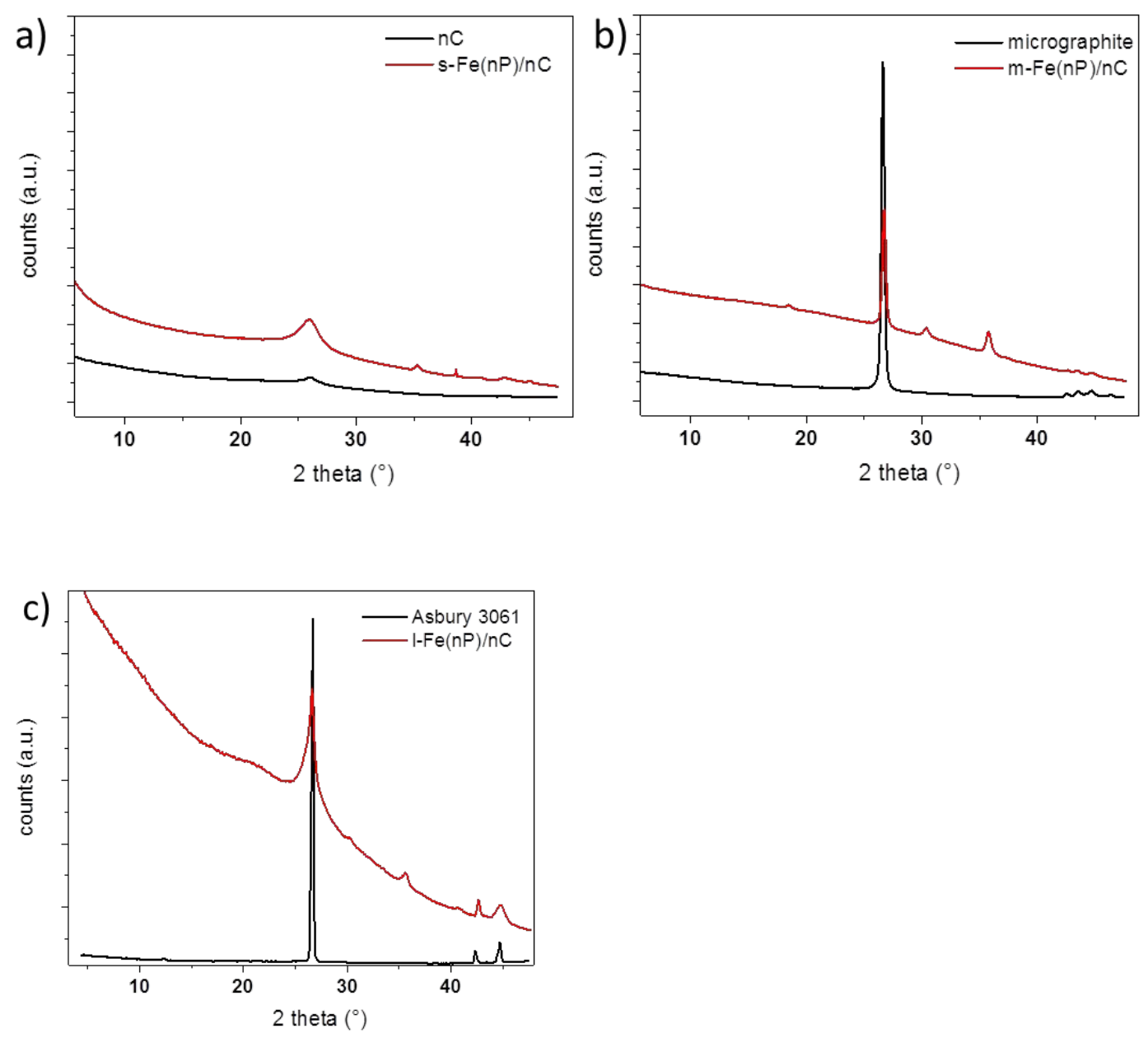

Figure $\mathbf{S} 7 \mathrm{XRD}$ analysis $(\mathrm{Cu} \mathrm{K-}-\alpha)$ of the different composite materials in comparison to the respective starting material left side: $\mathrm{s}-(\mathrm{Fe}(\mathrm{nP}) / \mathrm{nC})$, middle $\mathrm{m}-(\mathrm{Fe}(\mathrm{nP}) / \mathrm{nC})$, right side: $1-(\mathrm{Fe}(\mathrm{nP}) / \mathrm{nC})$ 

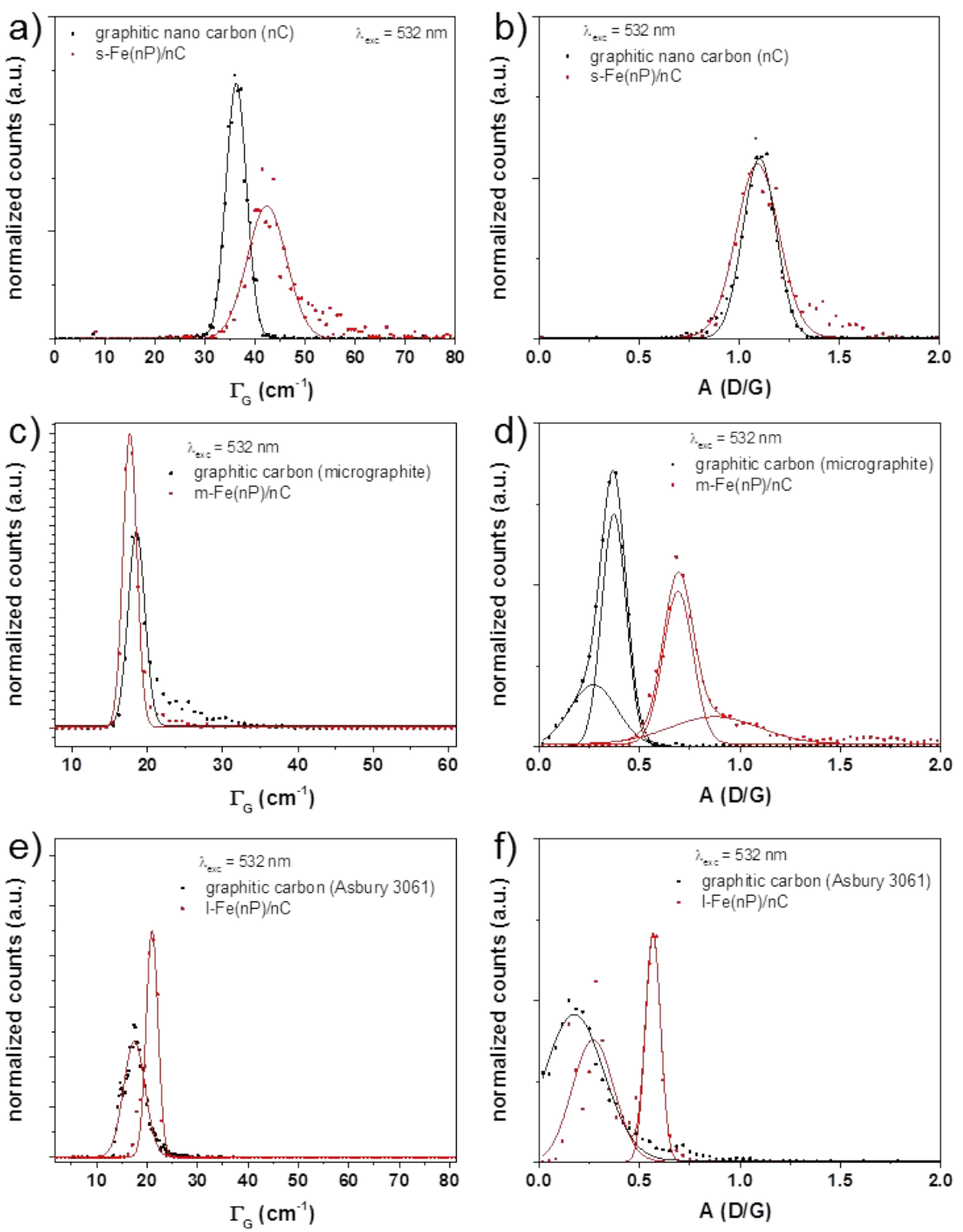

Figure S 8 Statistical Raman spectroscopic measurements $\lambda_{\text {exc }}=532 \mathrm{~nm}$ of the 3 starting graphite materials in comparison to the 3 different iron nanoparticle carbon composite materials based on the analysis of 1681 spectra. Left side: histograms of the width of the G-mode. Right side: $A(D / G)$ values. 


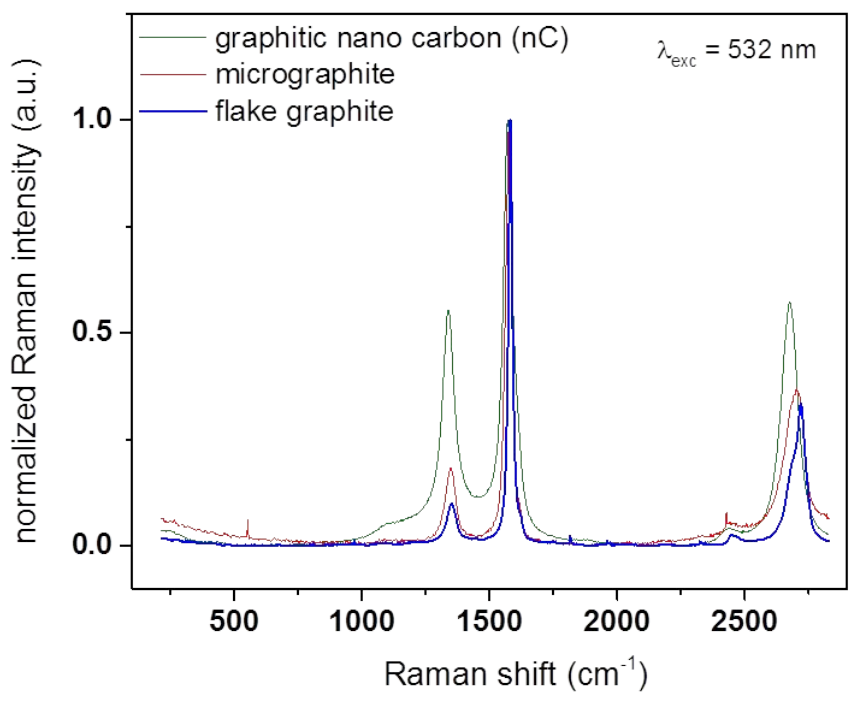

Figure S 9 Mean Raman spectra of the 3 starting graphite materials measuered at excitation wavelength: $\lambda_{\text {exc }}=532$ nm.
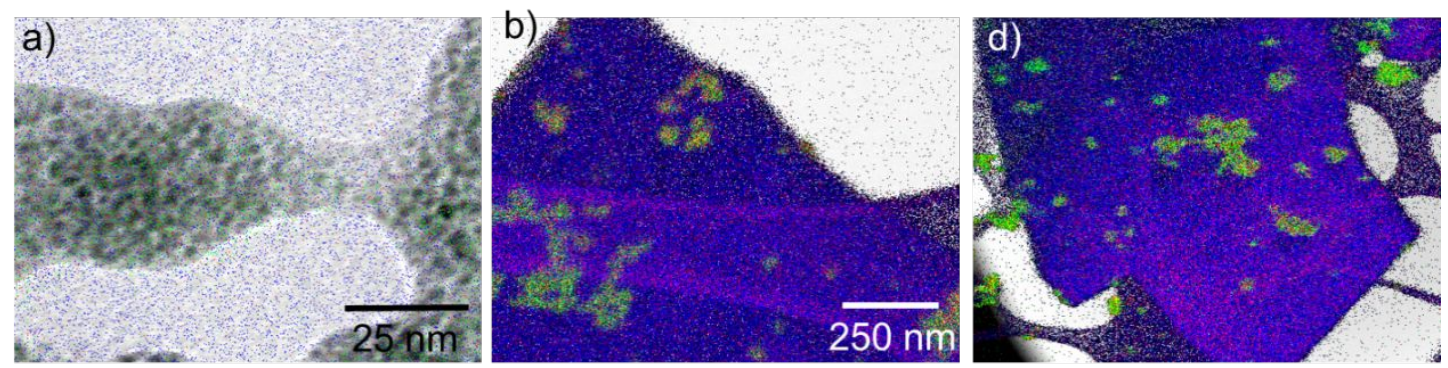

Figure S 10 Composite STEM/EDX mapping of the three composite materials (individual maps in the main manuscript), carbon (blue), oxygen (red) and iron(green) of the three different composite materials a) s-Fe(nP)/nC, b) $\mathrm{m}-\mathrm{Fe}(\mathrm{nP}) / \mathrm{nC}, 1-\mathrm{Fe}(\mathrm{nP}) / \mathrm{nC}$. 

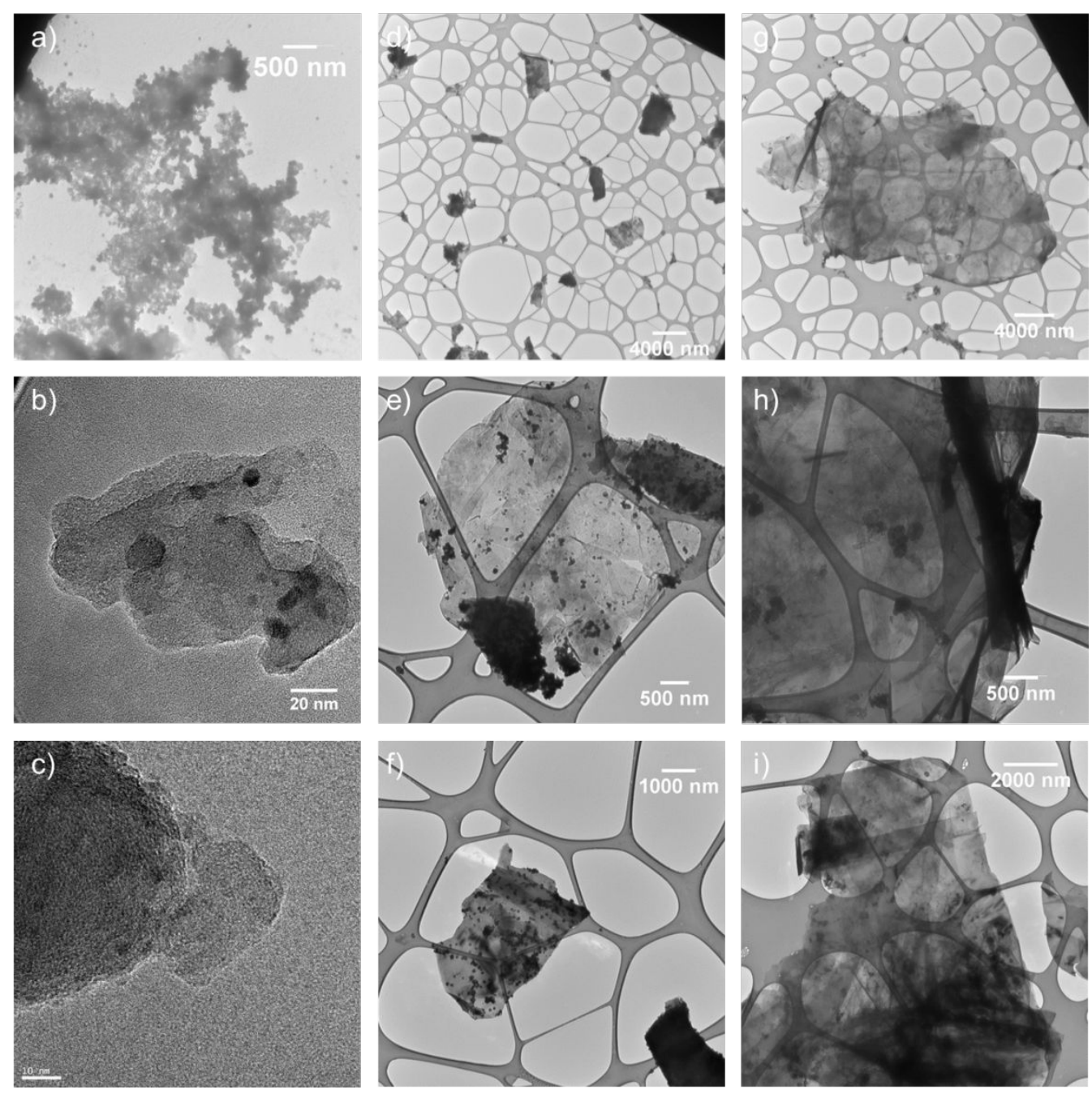

Figure S 11 TEM analysis of the different composite materials a), b), c) s-Fe(nP)/nC, d), e), f), m-Fe(nP)/nC, g), h), i), l-Fe(nP)/nC. a), d, g) overview images of the general morphology of the different composite materials at lower magnification. Higher magnification images of the different composite materials at higher magnification showing individual objects b), c) e), f), h), i). The presence of both, nanoparticles and carbon layers can be seen for samples in each sample. The size of the carbon layers is significantly different for the three different samples (see also Fig S11). Iron nanoparticles are formed attached to the carbon flakes regardless of the choice of the starting. The size of the nanoparticles are larger, the larger the respective carbon flakes are. 

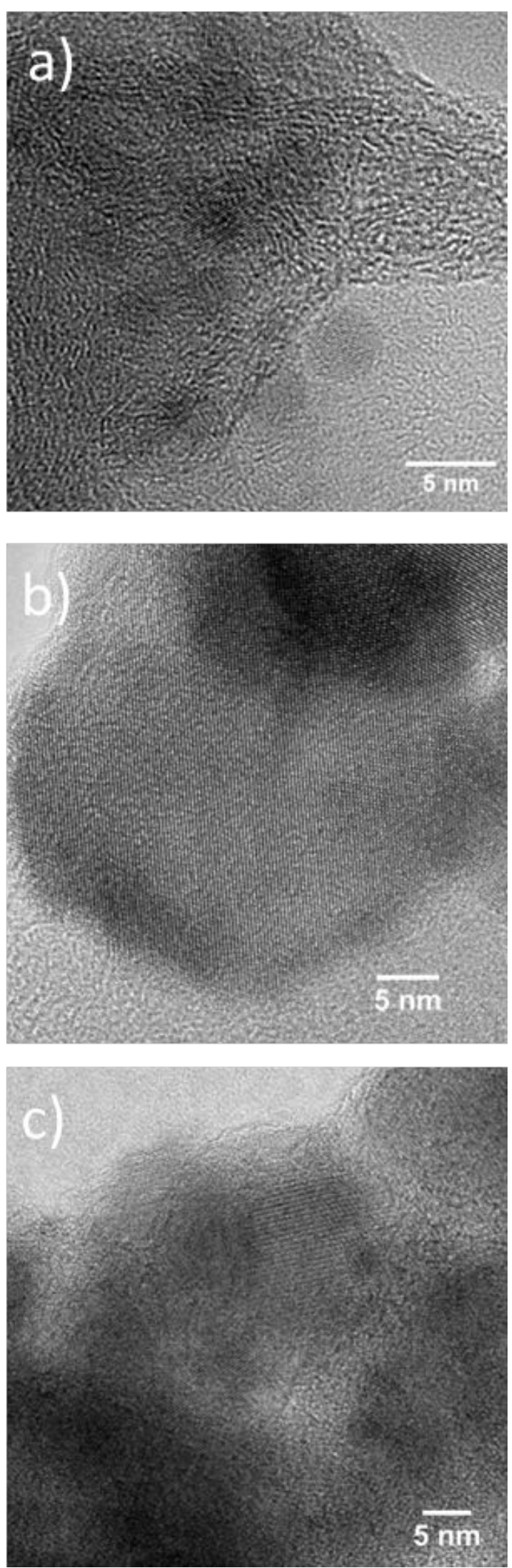

Figure S 12 HR-TEM image at high magnification demonstrating the crystallinity of the generated nanoparticles, a) $\mathrm{s}-\mathrm{Fe}(\mathrm{nP}) / \mathrm{nC}, \mathrm{b}) \mathrm{m}-\mathrm{Fe}(\mathrm{nP}) / \mathrm{nC}, 1-\mathrm{Fe}(\mathrm{nP}) / \mathrm{nC}$. 

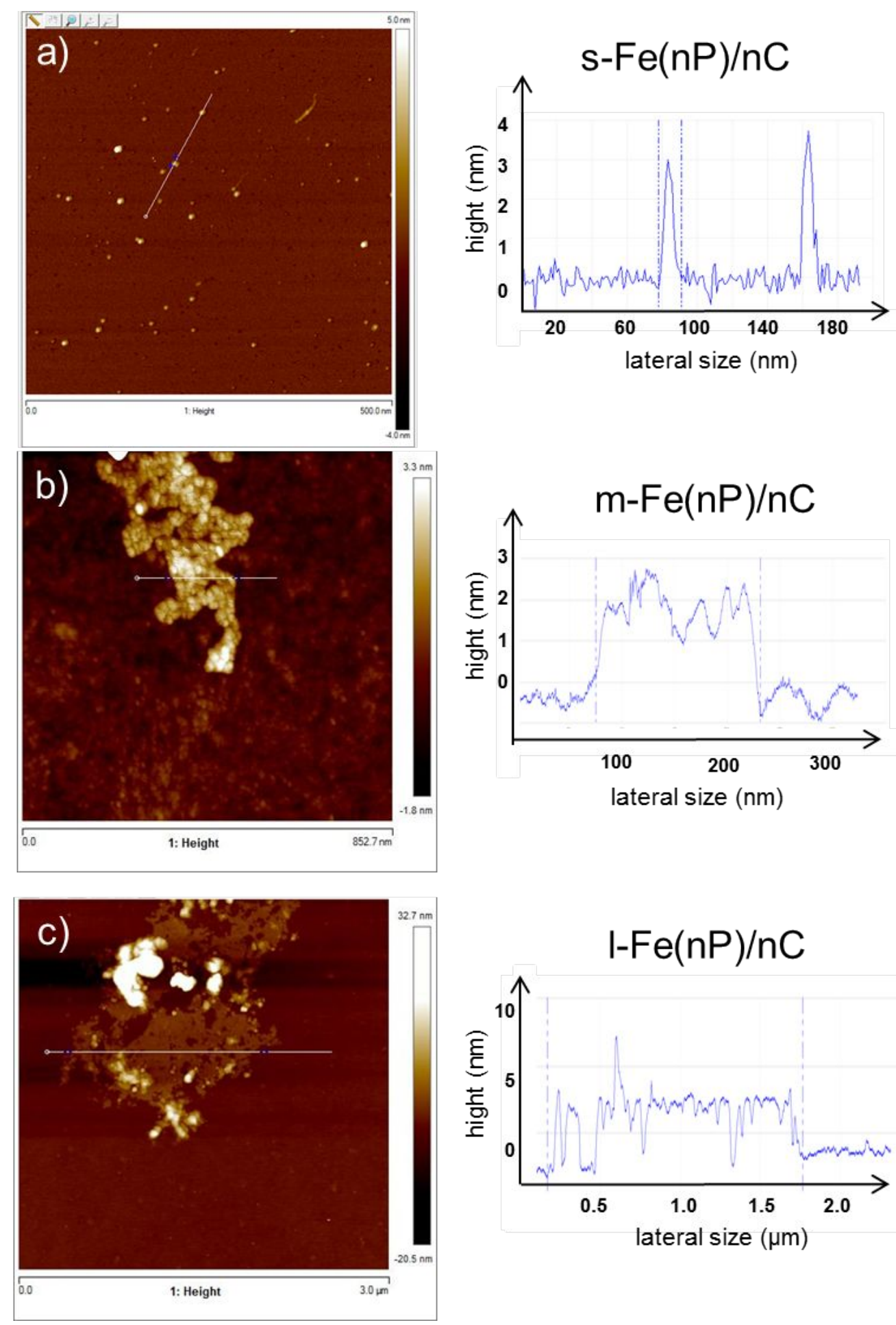

Figure S 13 a) AFM images of the composite materials and corresponding high profil a), s- $\mathrm{Fe}(\mathrm{nP}) / \mathrm{nC}$ b) $\mathrm{m}-\mathrm{Fe}(\mathrm{nP}) / \mathrm{nC}$ and c) $1-\mathrm{Fe}(\mathrm{nP}) / \mathrm{nC}$.

Electrochemical Characterisation: 

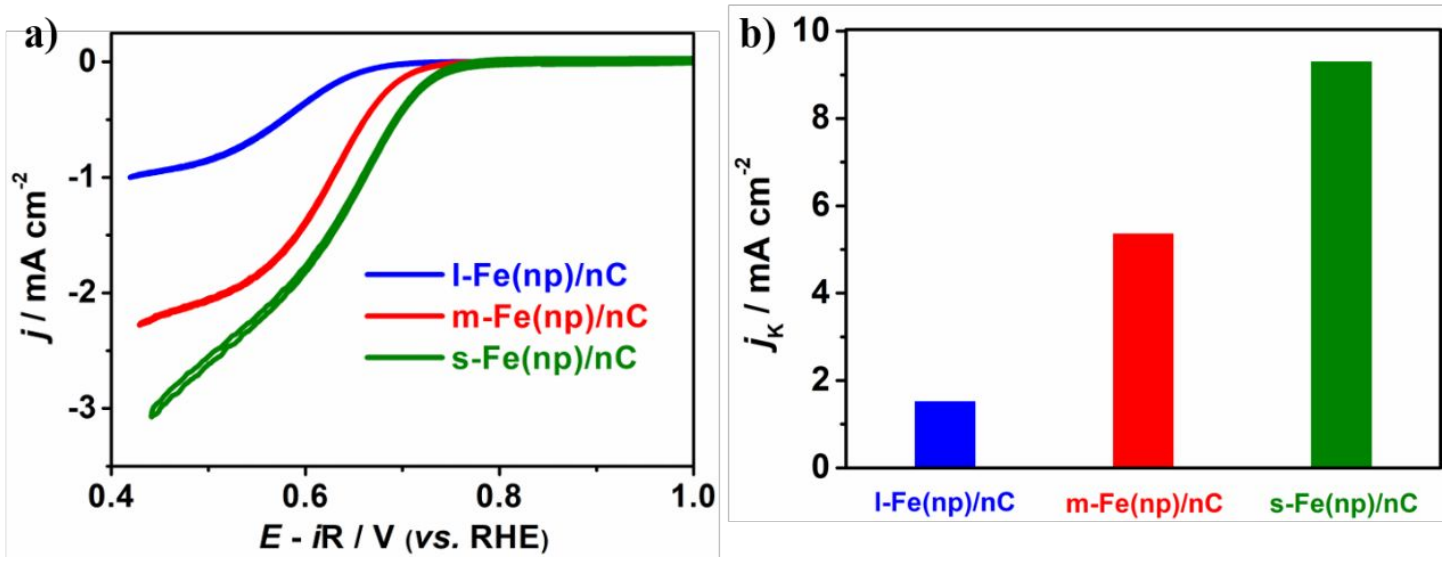

Figure S 14. a) Comparation of limiting current densities of $1-, \mathrm{m}$ - and s-Fe(np)/nCs obtained with $\mathrm{RDE}$ at $1600 \mathrm{rpm}$ in $\mathrm{O}_{2}$-saturated $0.1 \mathrm{M} \mathrm{KOH} . \mathrm{b})$ Kinetic current densities $\left(\mathrm{j}_{\mathrm{K}}\right)$ of l-, $\mathrm{m}$ - and s-Fe(np)/nC achieved from corresponding K-L plots.

a)

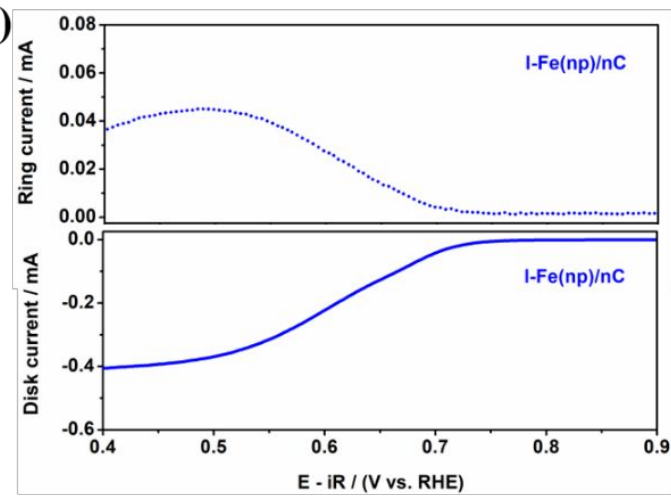

b)

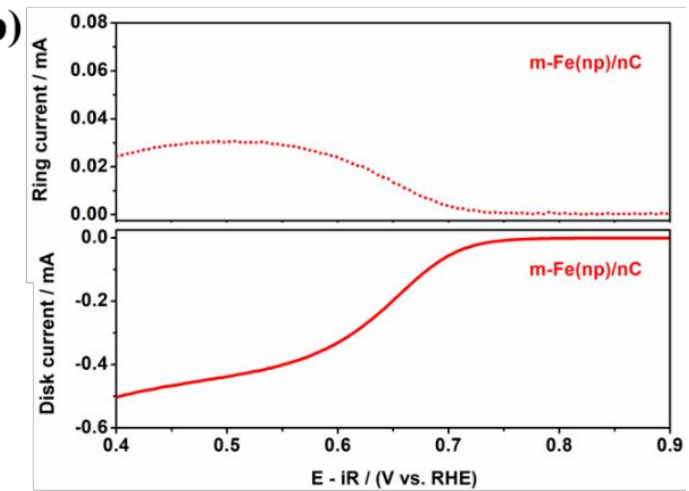

c)

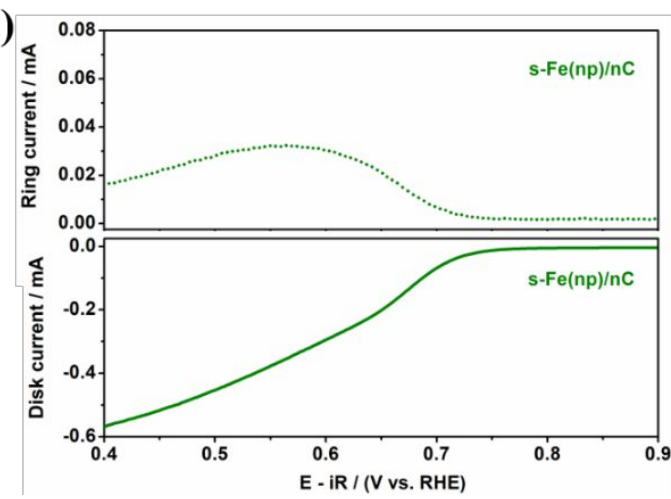

Figure S 15 RRDE voltammograms of a) $1-\mathrm{Fe}(\mathrm{np}) / \mathrm{nC}, \mathrm{b}) \mathrm{m}-\mathrm{Fe}(\mathrm{np}) / \mathrm{nC}$ and c) s-Fe(np)/nC obtained in $\mathrm{O}_{2}$-saturated $0.1 \mathrm{M} \mathrm{KOH}$ at $1600 \mathrm{rpm}$. Ring current (upper graph) and disk current (lower graph) are shown in dotted and solid lines, respectively. The disk potential was scanned at $10 \mathrm{mV} \mathrm{s}^{-1}$ while the ring potential was fixed at $1.3 \mathrm{~V}$ vs RHE. Presented after iR-compensation. 

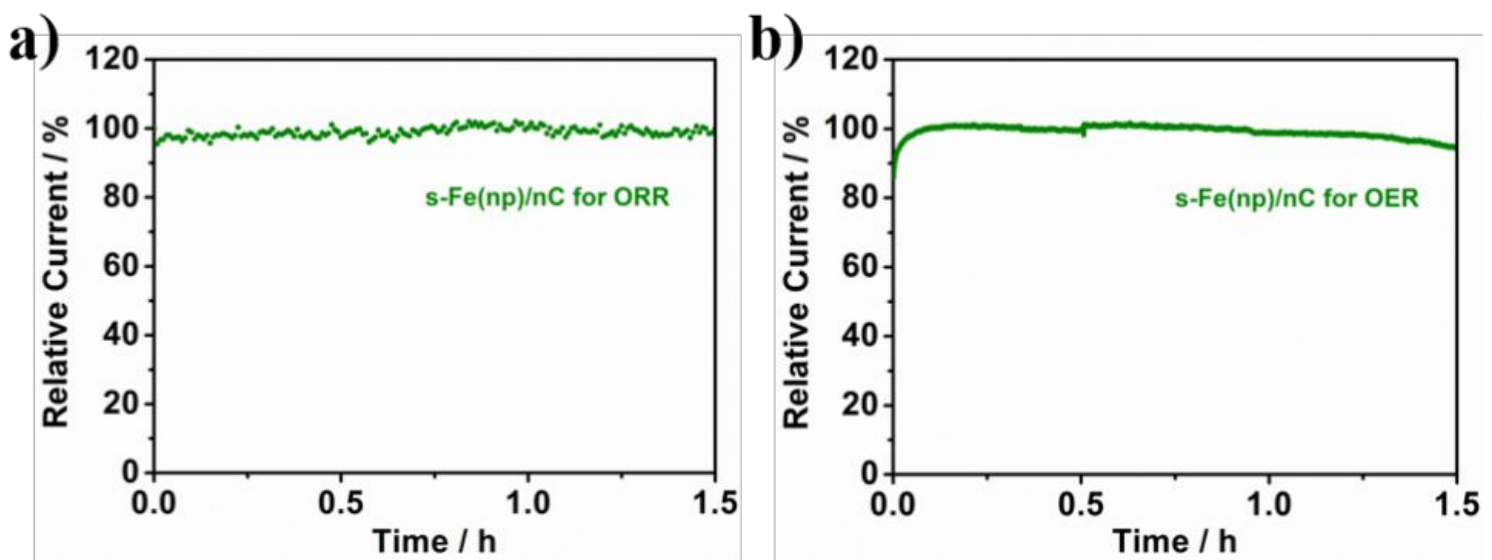

Figure S 16 Chronoamperometric responses of the s-Fe(np)/nC for a) ORR recorded at $0.7 \mathrm{~V}$ vs RHE, and b) OER recorded at $1.68 \mathrm{~V}$ vs RHE in O2-saturated $0.1 \mathrm{M} \mathrm{KOH}$ solution under $1600 \mathrm{rpm}$.

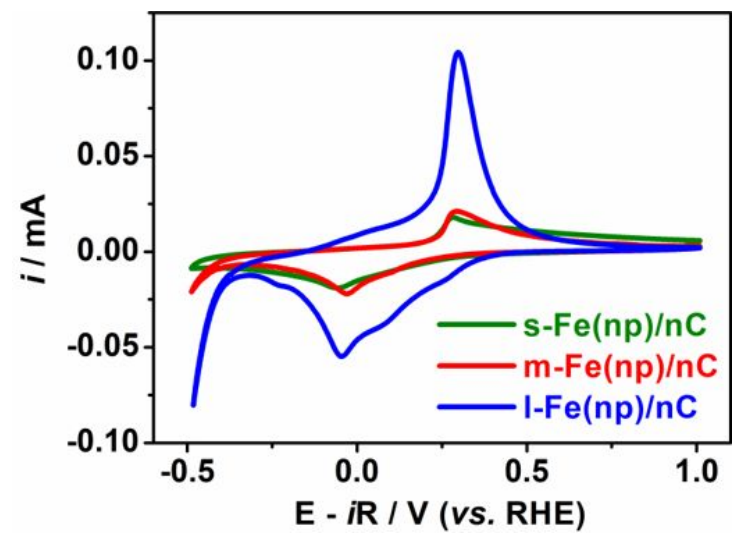

Figure S 17 Quantification of electroactive $\mathrm{Fe}$ species by coulometry of the $\mathrm{FeO}$ peak for $\mathrm{Fe}(\mathrm{np}) / \mathrm{nC}$ electrodes.

Table ST 2. Comparison of the ORR performance for different $\mathrm{Fe}(\mathrm{np}) / \mathrm{nC}$ catalysts.

\begin{tabular}{|c|c|c|c|c|}
\hline Sample & $\begin{array}{c}\text { Onset potential } \\
\left(\boldsymbol{E}_{\text {onset }}\right) / \mathbf{V}\end{array}$ & $\begin{array}{c}\text { electron transfer } \\
\text { number (n) at } \mathbf{0 . 4 0} \mathbf{~ V}\end{array}$ & $\begin{array}{c}\text { kinetic current density } \\
\left(\boldsymbol{j}_{\mathbf{K}}\right) \text { at } \mathbf{0 . 4 5} \mathbf{~} / \mathbf{~ m A} \\
\mathbf{c m}^{-2}\end{array}$ & $\begin{array}{c}\text { Quantification of } \\
\text { Fe species }(\mathbf{Q}) / \mathbf{~ m C}\end{array}$ \\
\hline $\mathrm{s}-\mathrm{Fe}(\mathrm{np}) / \mathrm{nC}$ & 0.79 & 3.60 & 9.3 & 0.30 \\
\hline $\mathrm{m}-\mathrm{Fe}(\mathrm{np}) / \mathrm{nC}$ & 0.75 & 3.37 & 5.4 & 0.33 \\
\hline $1-\mathrm{Fe}(\mathrm{np}) / \mathrm{nC}$ & 0.73 & 2.96 & 1.5 & 1.00 \\
\hline
\end{tabular}




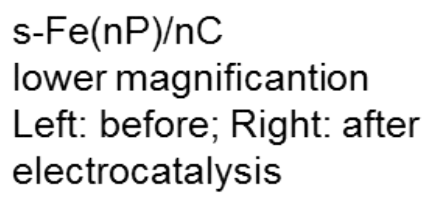

$\mathrm{I}-\mathrm{Fe}(\mathrm{nP}) / \mathrm{nC}$ higher magnificantion Left: before; Right: after electrocatalysis
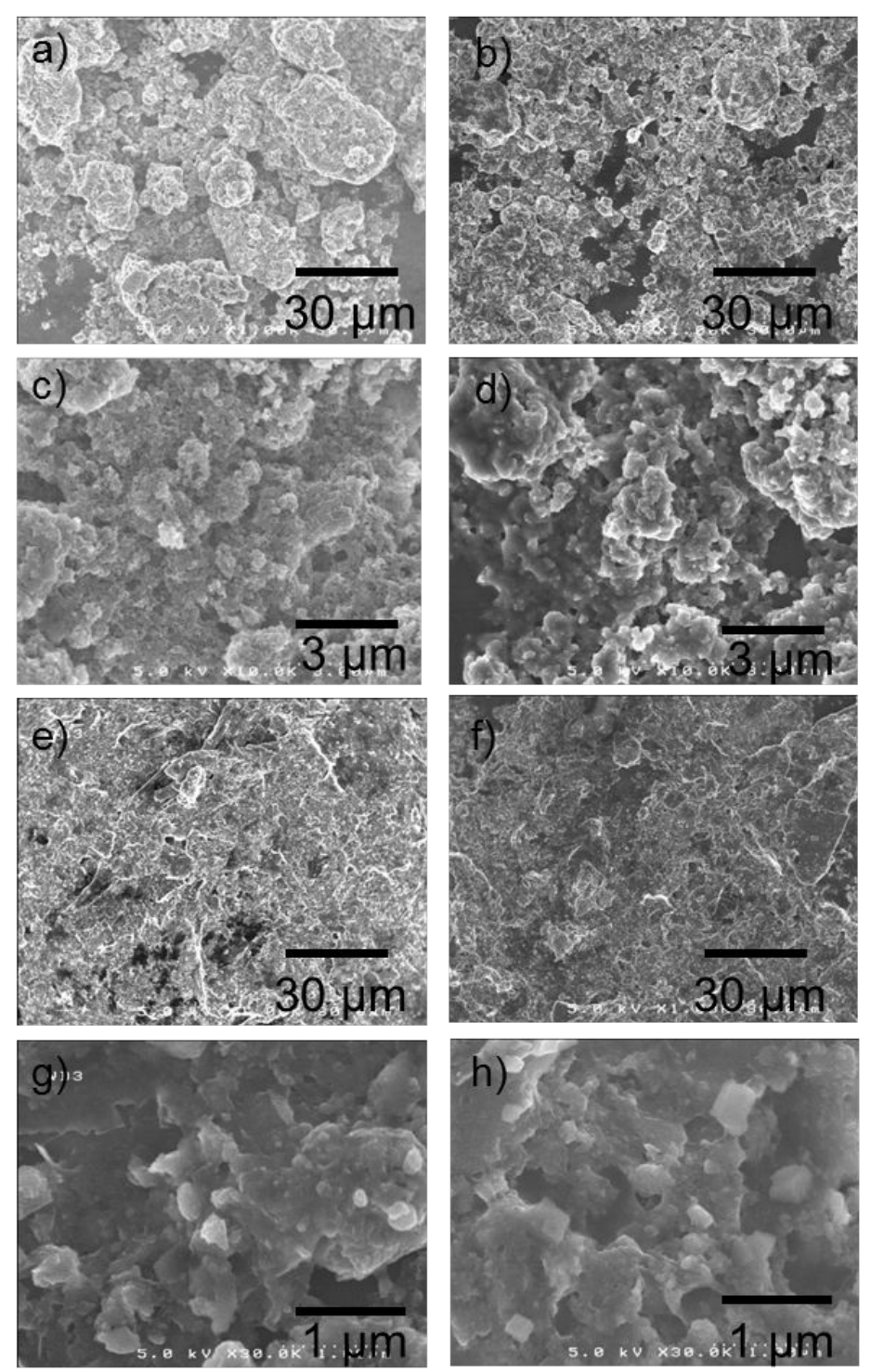

Figure S 18 SEM images of the electrode of the s-Fe(nP)/nC and l-Fe(nP)/nC composite material, prepared by dropcasting on a glassy carbon plate, before electrochemical experiments a), e) lower magnification, c), g) higher magnification and after electrochemical experiments b), f) lower magnification and d), h) higher magnification. SEM images.

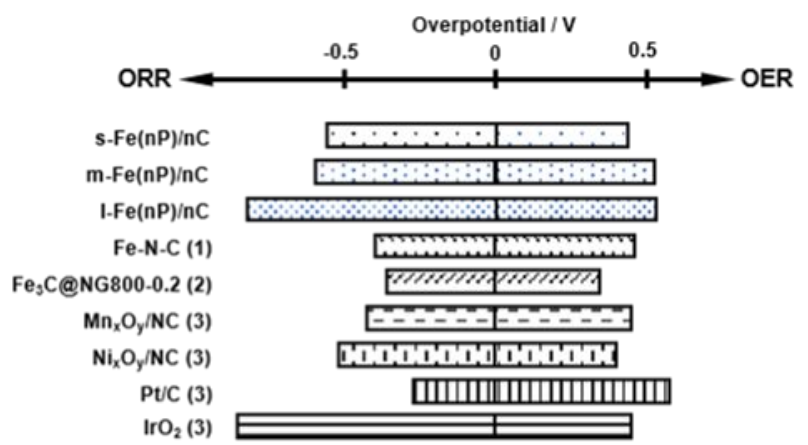

Figure S 19 Comparison of combined overpotential for ORR and OER of $\mathrm{Fe}(\mathrm{nP}) / \mathrm{nCs}$ and recently reported bi-functional catalysts for oxygen electrocatalysis ( $\eta_{\mathrm{OER}}$ at $5 \mathrm{~mA} \mathrm{~cm}{ }^{-2}$, while $\eta_{\mathrm{ORR}}$ at $1 \mathrm{~mA} \mathrm{~cm} \mathrm{~cm}^{-2}$ ). 


\section{References:}

(1) Dresp, S.; Luo, F.; Schmack, R.; Kuhl, S.; Gliech, M.; Strasser, P. Energy Environ. Sci. 2016, 9 , 2020.

(2) Jiang, H.; Yao, Y.; Zhu, Y.; Liu, Y.; Su, Y.; Yang, X.; Li, C. ACS Appl. Mater. Interfaces 2015, 7, 21511.

(3) Masa, J.; Xia, W.; Sinev, I.; Zhao, A.; Sun, Z.; Grutzke, S.; Weide, P.; Muhler, M.; Schuhmann, W. Angew. Chem. Int. Ed. 2014, 53, 8508. 